\title{
Correction to: Challenges and opportunities for graduate students in public health during the COVID-19 pandemic
}

\author{
Kristina Jenei $^{1}$ - Chenoa Cassidy-Matthews ${ }^{1} \cdot$ Punit Virk $^{1} \cdot$ Bethel Lulie $^{2} \cdot$ Kalysha Closson $^{1}$
}

Published online: 16 June 2020

(C) The Canadian Public Health Association 2020

\section{Correction to: Canadian Journal of Public Health https://doi.org/10.17269/s41997-020-00349-8}

This article was updated to correct the spelling of Chenoa Cassidy-Matthews' name: it is correct as displayed here.

Publisher's note Springer Nature remains neutral with regard to jurisdictional claims in published maps and institutional affiliations.

The online version of the original article can be found at https://doi.org/ $10.17269 / \mathrm{s} 41997-020-00349-8$

Kalysha Closson

kclosson@cfenet.ubc.ca

1 School of Population and Public Health, University of British Columbia, Vancouver, BC, Canada

2 Faculty of Health Sciences, Simon Fraser University, Burnaby, BC, Canada 